\title{
Cu-doped ceria: oxygen vacancy formation made easy
}

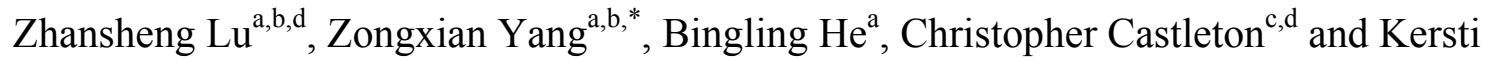 \\ Hermansson ${ }^{\mathrm{d}, \mathrm{e},}$, \\ ${ }^{\mathrm{a} C o l l e g e ~ o f ~ P h y s i c s ~ a n d ~ I n f o r m a t i o n ~ E n g i n e e r i n g, ~ H e n a n ~ N o r m a l ~ U n i v e r s i t y, ~ X i n x i a n g, ~}$ \\ Henan 453007, China \\ ${ }^{b}$ Henan Key Laboratory of Photovoltaic Materials, Xinxiang 453007, China \\ ${ }^{c}$ School of Science and Technology, Nottingham Trent University, Nottingham, NG11 \\ $8 N S, U K$ \\ ${ }^{d}$ Materials Chemistry, The Angström Laboratory, Uppsala University, Box 538, \\ SE-75121 Uppsala, Sweden \\ ${ }^{e}$ Theoretical Chemistry, School of Biotechnology, Royal Institute of Technology, \\ SE-10691 Stockholm, Sweden
}

\begin{abstract}
$\mathrm{DFT}+\mathrm{U}$ calculations of $\mathrm{Cu}$-doped bulk ceria are presented. The first oxygen vacancy in $\mathrm{Cu}$-doped ceria forms almost spontaneously and the second vacancy is also easily created. Whether zero, one or two oxygen vacancies, the $\mathrm{Cu}$ dopant is in the form $\mathrm{Cu}(+\mathrm{II})$, and prefers to be 4-coordinated in a close to planar structure. Charge compensation, structural relaxation and available $\mathrm{Cu}-\mathrm{O}$ states all play a role in lowering the $\mathrm{O}$ vacancy formation energies, but to different degrees when the first and second oxygen vacancies are formed. The $\mathrm{Cu}$-doped ceria(111) surface system behaves in a similar fashion.
\end{abstract}

Keywords: Ceria; $\mathrm{CeO} 2$ bulk; $\mathrm{Cu}$-doped $\mathrm{CeO} 2$; Oxygen vacancy formation; relaxation energy; $\mathrm{Cu}(+\mathrm{II})$

\footnotetext{
*Authors to whom correspondence should be addressed.

Electronic mails: yzx@henannu.edu.cn (Z Yang); kersti@mkem.uu.se (K Hermansson)
} 


\section{Introduction}

Several studies in the literature have shown that copper-ceria systems $\left(\mathrm{Cu}-\mathrm{CeO}_{2}\right)$ are efficient catalysts for the water-gas shift (WGS) reaction (see, for example, Ref. [1]), the reduction of $\mathrm{SO}_{2}$ by $\mathrm{CO}$ [2], and the selective hydrogen combustion reaction [3]. $\mathrm{Cu}-\mathrm{CeO}_{2}$ systems are also interesting in context of solid oxide fuel cell (SOFC) technology [4] due to the excellent electronic conductivity of $\mathrm{Cu}$ and the high catalytic activity of $\mathrm{CeO}_{2}$ for $\mathrm{C}-\mathrm{H}$ bond breaking in $\mathrm{CH}_{4}$, especially when mixed with particular noble metals dopants [5].

In the present paper we discuss $\mathrm{Cu}$-doped ceria. For the WGS and the SOFC applications, the literature suggests that it is copper metal at the $\mathrm{Cu}$ /ceria interface that is particularly active. In other cases, however, $\mathrm{Cu}$-doped ceria surfaces are believed to be the active catalyst, as in the case of $\mathrm{SO}_{2}$ reduction by $\mathrm{CO}$ referred to above. On the whole, it should be noted that the exact form of $\mathrm{Cu}$ in $\mathrm{Cu}-\mathrm{Ce}-\mathrm{O}$ catalysts is still a matter of debate and depends much on the particular preparation protocol used. For example, Avgouropoulos et al. [6] concluded that either finely dispersed copper oxide, or a solid solution, or alternatively a combination of these two may be formed on the surface of ceria in the $\mathrm{CuO}-\mathrm{CeO}_{2}$ catalysts. Djinovic et al. [7] reported both nanosized and bulk-like $\mathrm{CuO}$ species on the ceria surfaces of their $\mathrm{Cu}-\mathrm{Ce}-\mathrm{O}$ catalysts, but in addition presented evidence for strong metal oxide-support interactions (SMSI) with $\mathrm{CuO}$ partly integrated into $\mathrm{CeO}_{2}$, forming a solid solution.

Controlled experiments reported in the literature give some information about the structure and dynamics of $\mathrm{Cu}$-doped ceria solid solutions. Electrical conductivity measurements have shown that a $\mathrm{Cu}_{\mathrm{x}} \mathrm{Ce}_{1-\mathrm{x}} \mathrm{O}_{2-s}(0 \leq x \leq 0.10)$ solid solution exhibits good oxide-ion conductivity [8]. As for structure, Bera et al. [9] presented a comprehensive experimental study of $\mathrm{Cu}$-doped ceria samples using a range of methods; their EXAFS analyses for $\mathrm{Cu}_{\mathrm{x}} \mathrm{Ce}_{1-\mathrm{x}} \mathrm{O}_{2-\delta}$ samples with $x$ equal to $0.03,0.05$ and 0.10 suggested that $\mathrm{Cu}$ has three oxygen atoms in its first coordination shell, located at a distance of $1.96 \AA$. Wang et al. [10] performed synchrotron-based X-ray diffraction (XRD) and EXAFS measurements for $\mathrm{x}=0.05,0.1$ and 0.2 (supported by quantum-mechanical calculations). Their EXAFS fits indicated a $\mathrm{Cu}-\mathrm{O}$ coordination number of 5-6 (while their quantum-mechanical calculations suggested that the $\mathrm{Cu}$ atom in bulk ceria has four oxygen atom neighbors at a distance of 1.92-1.95 $\AA$ ). Moreover, in their experiments they also found that the $\mathrm{Cu}$ dopants always gave rise to a corresponding number of $\mathrm{O}$ vacancies, i.e. that vacancy formation is very much facilitated by $\mathrm{Cu}$ doping and the oxygen storage capacity remarkably enhanced [10]. Here, we will explore exactly that property by means of quantum-mechanical calculations.

Only a few quantum-mechanical studies of the structure and electronic properties of the $\mathrm{Cu}-\mathrm{CeO}_{2}$ systems have appeared in the literature. To the best of our knowledge all these studies explored unreduced samples, i.e. without $\mathrm{O}$ vacancies. As mentioned, Wang et al. studied bulk $\mathrm{CeO}_{2}, \mathrm{CuO}, \mathrm{Cu}_{2} \mathrm{O}, \mathrm{Cu}_{0.25} \mathrm{Ce}_{0.75} \mathrm{O}_{2}$ and $\mathrm{Cu}_{0.125} \mathrm{Ce}_{0.875} \mathrm{O}_{2}$ [10], while Shapovalov and Metiu [11] reported data for the $\mathrm{Cu}-\mathrm{O}$ coordination structure for $\mathrm{Cu}$-doped $\mathrm{CeO}_{2}(111)$ (as part of a larger study of $\mathrm{CO}$ oxidation on Au-doped ceria surface). In Ref. [12], we discussed results for $\mathrm{Cu}$ adsorption on top of the $\mathrm{CeO}_{2}(111)$ surface (this gave a $\mathrm{Cu}(+\mathrm{I})$ ion) and the weaker adsorption above an $\mathrm{O}$ vacancy (gave a negative $\mathrm{Cu}$ ion) as part of a study of $\mathrm{CO}$ and $\mathrm{CO}_{2}$ interacting with the $\mathrm{Cu}-\mathrm{CeO}_{2}$ system. Branda et al. [13] also studied a $\mathrm{Cu}$ atom on top of an O-terminated $\mathrm{CeO}_{2}(111)$ (with a variety of $\mathrm{LDA}+\mathrm{U}$ and $\mathrm{GGA}+\mathrm{U}$ flavors) in a study of $\mathrm{Cu}, \mathrm{Ag}$ and $\mathrm{Ag}$ on ceria(111). They found $\mathrm{Cu}$ symmetrically surrounded by three $\mathrm{O}$ atoms to be the most favorable 
adsorption site with all the different methods they tried, as we also did in Ref. [12], and as us, they found that $\mathrm{Cu}$ oxidizes to $\mathrm{Cu}(+\mathrm{I})$. In Ref. [12], we also studied the $\mathrm{Cu}$-doped ceria(111) surface.

In the current density functional theory (DFT) study we continue to study the effect of $\mathrm{Cu}$-doping, this time for bulk ceria. We will find that the first oxygen vacancy in $\mathrm{Cu}$-doped ceria is formed almost spontaneously and the formation of a second vacancy is also facile. We will find that charge compensation, structural relaxation and available $d$ - and $f$-electron levels all play a role here, but to different degrees when the first and second oxygen vacancies are formed. We end the paper by making some comparisons between bulk and surface of $\mathrm{Cu}$-doped ceria and in the conclusion section we give some general remarks about the effect of aliovalent transition metal dopants on the $\mathrm{O}$ vacancy formation in ceria.

\section{Computational Details}

\subsection{Electronic structure calculations}

Spin-polarized DFT calculations were performed using the Vienna ab initio simulation package (VASP) package $[14,15]$ with the projector augmented wave (PAW) method $[16]$ and the Perdew-Burke-Ernzerhof (PBE) functional [17]. The cerium $5 s, 5 p, 5 d, 4 f, 6 s$, the oxygen $2 s, 2 p$ and the copper $3 d, 4 s$ electrons were treated as valence electrons.

Based on the discussion in Ref. [18] and some references therein, the PBE+U method [19] was applied to accurately describe the strong on-site Coulomb repulsion of the Ce $4 f$ electrons. Here an effective $\mathrm{U}$ value of $5.0 \mathrm{eV}$ was chosen to give a balanced and adequate description of the atomic and electronic structures for both stoichiometric $\left(\mathrm{CeO}_{2}\right)$ and partially reduced ceria $\left(\mathrm{CeO}_{2-\mathrm{x}}\right)$ $[18,20]$. In all of our calculations, plane waves were used as the basis set, with an energy cutoff of $30 \mathrm{Ry}$. The structure optimizations were performed until the force on each atom was smaller than $0.02 \mathrm{eV} / \AA$. An atomic charge analysis was performed according to the Bader scheme [21].

\subsection{Model systems and the definition of the $O$ vacancy formation energy}

Crystalline $\mathrm{CeO}_{2}$ bulk has the fluorite structure where one Ce atom is surrounded by eight oxygen atoms (similar to the framed region in Fig. 1a). The current calculations for stoichiometric ceria gave an equilibrium lattice parameter of $5.480 \AA$; the experimental room-temperature value is $5.411 \AA[22]$.

For Cu-doped bulk, a supercell containing 96 atoms was built from the conventional 12-atom cubic unit cell of $\mathrm{CeO}_{2}$ with a $2 \times 2 \times 2$ replication and one $\mathrm{Ce}$ atom was replaced by a $\mathrm{Cu}$ atom. This corresponds to a dopant concentration of $3 \%$ and is denoted as $\mathrm{Ce}_{0.97} \mathrm{Cu}_{0.03} \mathrm{O}_{2}$. For one of the defect structures, namely $\mathrm{Cu}$-doped ceria, the structure was optimized using either a 3 $k$-point grid (corresponding to a $3 \times 3 \times 3$ Monkhorst-Pack grid [23]) or only one $k$ point (the gamma point). The total energy was found to be the same within $0.01 \mathrm{eV}$ and the local structure around the $\mathrm{Cu}$ defect was almost identical. Here we have subsequently used one $k$ point and a Gaussian smearing parameter Sigma of $0.01 \mathrm{eV}$ for all the calculations on the 96-site cell. The doped system was assumed to keep the cubic structure and therefore forced to do so, and the cell parameter and atomic positions were optimized, resulting in a cell change of less than $0.05 \%$, compared to the undoped case. Thus for all of the systems studied in this paper, the cell parameters were fixed at the corresponding undoped values.

The $\mathrm{O}$ vacancy formation energy $\left(E_{\mathrm{vac}}\right)$ was calculated after optimization of the atomic positions for each system according to 
First $E_{\text {vac }}=E($ cell with one $\mathrm{O}$ vacancy $)+1 / 2 E\left(\mathrm{O}_{2}\right)-E($ cell without an $\mathrm{O}$ vacancy $)$

Second $E_{\text {vac }}=E($ cell with two $\mathrm{O}$ vacancies $)+1 / 2 E\left(\mathrm{O}_{2}\right)-E($ cell with one $\mathrm{O}$ vacancy $)$

$E\left(\mathrm{O}_{2}\right)$ is the total energy for the ground state of an optimized oxygen molecule in the gas phase. A positive value of $E_{\mathrm{vac}}$ means that energy is needed to create a vacancy.

As an alternative to using the oxygen molecule as a reference state in the formulas above, and in an attempt to avoid the DFT error connected to the description of the $\mathrm{O}_{2}$ molecule, the $\mathrm{O}$ atom can be used as a reference state instead. The difference between these definitions of $E_{\mathrm{vac}}$ is exactly half the binding energy for $\mathrm{O}_{2}$. Our calculated value for the binding energy is $6.18 \mathrm{eV}$.

\section{Results and discussion}

Table I lists quantities related to the interaction between the $\mathrm{Cu}$ dopant and bulk ceria, namely, $E_{\mathrm{vac}}, R(\mathrm{Cu}-\mathrm{O})$ and the net (Bader) charge that the $\mathrm{Cu}$ atom acquires in the various systems. The optimized structures and the details of the electronic structure such as the total density of states (TDOS) and the corresponding electron densities are shown in the figures. Results for the ceria(111) surface are given in Table I for comparison and are discussed in Section 3.3.

\subsection{Cu-doped bulk ceria}

A Ce atom was replaced by a $\mathrm{Cu}$ atom in bulk $\mathrm{CeO}_{2}$ in the 96-atom supercell. The $\mathrm{Cu}$ dopant was thus initially placed at the center of one of the cubes formed by the 8 oxygen atoms surrounding the $\mathrm{Ce}$ atom in ceria. The optimization brought the $\mathrm{Cu}$ atom all the way down to the face of the $\mathrm{O}$ cube. At this new position, the $\mathrm{Cu}$ atom is 4-coordinated in a close-to-planar structure (Fig. 1a) similar to the $\mathrm{Cu}$ coordination in $\mathrm{CuO}$ bulk (Fig. 1b). The $\mathrm{Cu}$ ion is seen to distort the ceria lattice by contracting the $\mathrm{O}$ square surrounding it and pushing away those $\mathrm{O}$ atoms which lost their cation neighbor when $\mathrm{Cu}$ moved away. The $\mathrm{Cu}$-dopant loses about 1.20 electrons according to the Bader charge analysis when incorporated in the ceria lattice, and thus becomes $\mathrm{Cu}^{+1.20}$. This is even a little more than the $\mathrm{Cu}$ charge in pure $\mathrm{CuO}$ bulk $\left(\mathrm{Cu}^{+1.02}\right)$, mainly due to the O-rich environment in ceria. The $\mathrm{Cu}$ dopant has only a small effect on the Ce charges but some of the $\mathrm{O}$ ions become less negative (by in total about 2 electrons), compared to undoped $\mathrm{CeO}_{2}$.

An $O$ vacancy was introduced as a nearest-neighbor (NN) to the $\mathrm{Cu}$ dopant, the structure was reoptimized, and $E_{\text {vac }}$ was calculated to $0.98 \mathrm{eV}$, which is much smaller than for undoped ceria (3.28 eV in our calculations). The $\mathrm{Cu}$ dopant is here coordinated by three $\mathrm{O}$ neighbors (Fig. $2 \mathrm{a}$; Table 1) and the four Ce cations surrounding the vacancy are all (nominally) $\mathrm{Ce}^{4+}$, contrary to the situation for undoped ceria where an $\mathrm{O}$ vacancy gives rise to two $\mathrm{Ce}^{4+}$ and two $\mathrm{Ce}^{3+}$ ions (nominal charges) next to the $\mathrm{O}$ vacancy. If instead an $\mathrm{O}$ atom which is a next-nearest neighbor (NNN) to the $\mathrm{Cu}$ dopant is removed (Fig. 2b; Table 1) we find that it is even easier to create an $\mathrm{O}$ vacancy: now $E_{\text {vac }}$ is only $0.30 \mathrm{eV}$. The coordination around $\mathrm{Cu}$ is here 4-fold, with $\mathrm{Cu}-\mathrm{O}$ bond lengths similar to those in the $\mathrm{CuO}$ crystal structure [24], where $\mathrm{Cu}^{2+}$ has four $\mathrm{O}$ neighbors within 1.90 to $2.00 \AA$ and the next-nearest $\mathrm{O}$ neighbors reside 0.8 to $0.9 \AA$ further away. Also here the four $\mathrm{Ce}$ cations surrounding the vacancy are (nominally) $\mathrm{Ce}^{4+}$ and their Bader charges differ very little from pure $\mathrm{CeO}_{2}$ (or unreduced $\mathrm{Cu}$-doped $\mathrm{CeO}_{2}$ ), mainly because the $\mathrm{O}$ vacancy reinstates the charge balance in the system and remedies the shortage of electrons caused by the lower valence of $\mathrm{Cu}(2+)$ compared to $\mathrm{Ce}(4+)$, i.e. makes the $\mathrm{O}$ ions more negative again.

The Bader charge of the nominal $\mathrm{Cu}^{2+}$ ion is +0.98 and +1.06 for the $\mathrm{NN}$ and $\mathrm{NNN}$ reduced 
cases, respectively. The $\mathrm{Cu}$ ion thus continues to be a $\mathrm{Cu}(+\mathrm{II})$ ion (cf. the Bader charges in $\mathrm{CuO}$ ) even after the $\mathrm{O}$ vacancy is formed close to it.

Since we find that the first $\mathrm{O}$ vacancy is essentially a spontaneous defect in $\mathrm{Cu}$-doped ceria (especially at the NNN position), the second $\mathrm{O}$ vacancy becomes particularly interesting in the context of this material's catalytic functionality. We created an $O$ vacancy dimer by removing the $\mathrm{O}$ atom neighboring the first (NNN) oxygen vacancy, as shown in Fig. 3. $E_{\mathrm{vac}}$ for the second $\mathrm{O}$ vacancy is $2.39 \mathrm{eV}$, which is still smaller than $E_{\mathrm{vac}}$ in stoichiometric ceria bulk. The local 4-fold $\mathrm{Cu}-\mathrm{O}$ coordination persists (Fig. 3; Table 1) and the $\mathrm{Cu}$ charge is +1.03 , i.e. very similar to the charge for one vacancy only. Two of the nominal $\mathrm{Ce}^{4+}$ cations neighboring the $\mathrm{O}$ vacancy are reduced to $\mathrm{Ce}^{3+}$ (denoted as "\#” in Fig. 3) and develop spin moments of about $1.0 \mu_{\mathrm{B}}$ each. The magnetic spin moment is $0.46 \mu_{\mathrm{B}}$ for the $\mathrm{Cu}$ dopant, resulting in a total spin moment of $2.83 \mu_{\mathrm{B}}$ for the supercell.

\subsection{The mechanisms facilitating the $\mathrm{O}$ vacancy formation with a $\mathrm{Cu}$ dopant}

It has been suggested in the literature that $E_{\mathrm{vac}}$ depends almost linearly on the ionic radius of the dopant ions for tetravalent elements doped into bulk ceria [25], This suggests that structural relaxation is the main factor governing the reduction of the $E_{\mathrm{vac}}$. What can be expected for the $\mathrm{Cu}$ dopant, an aliovalent dopant with lower valence $\left(\mathrm{Cu}^{2+}\right)$ as compared with the host cations $\left(\mathrm{Ce}^{4+}\right)$ ? Is structural relaxation or electronic effects the main factor responsible for the lowering of $E_{\mathrm{vac}}$ ?

To help answer this question we use a somewhat simplistic model and divide $E_{\text {vac }}$ into an elastic and an electronic part. More details about the procedure can be found in Ref. [26]. It involves calculating the total energies for all the unrelaxed reduced systems. For the first $\mathrm{O}$ vacancy (in the NNN position), two additional single-point calculations were therefore performed, namely, for the unrelaxed $\mathrm{CeO}_{1.97}$ and $\mathrm{Ce}_{0.97} \mathrm{Cu}_{0.03} \mathrm{O}_{1.97}$ bulk systems. This allowed us to calculate the energy cost to rigidly remove an $\mathrm{O}$ atom from the optimized $\mathrm{CeO}_{2}$ and $\mathrm{Ce}_{0.97} \mathrm{Cu}_{0.03} \mathrm{O}_{2}$ crystals, respectively. Subsequent relaxations of the two structures yielded energy gains of $1.40 \mathrm{eV}$ for $\mathrm{CeO}_{1.97}$ and $2.79 \mathrm{eV}$ for $\mathrm{Ce}_{0.97} \mathrm{Cu}_{0.03} \mathrm{O}_{1.97}$. Thus the energy gain due to the relaxation $\mathrm{Cu}$-doped ceria bulk is $1.39 \mathrm{eV}$ larger (namely, $2.79 \mathrm{eV}$ minus $1.40 \mathrm{eV}$ ) than for undoped ceria bulk. These energy gains are already "included" in the final $E_{\text {vac }}$ values of 3.28 and $0.30 \mathrm{eV}$ for undoped and Cu-doped ceria bulk.

Thus, out of the total dopant-induced lowering of $E_{\mathrm{vac}}$ by $2.98 \mathrm{eV}$, we find that $1.39 \mathrm{eV}$ is due to the additional relaxation induced by the dopant. This is a large, but not the largest, contribution to the lowering of the vacancy formation energy, and is mainly due to the different radii of the dopant $\left(0.74 \AA\right.$ for $\left.\mathrm{Cu}^{2+}\right)$ and the host cation $\left(0.92 \AA\right.$ for $\left.\mathrm{Ce}^{4+}\right)$ [27]. The remainder $(1.59 \mathrm{eV})$ must be attributed to the changes in electronic structure induced by the $\mathrm{Cu}^{2+}$ dopant. Wang et al. [10] ascribe the easy formation of $\mathrm{O}$ vacancies in $\mathrm{Cu}$-doped bulk ceria to a large strain in the ceria lattice introduced by the $\mathrm{Cu}$ dopant.

The second $E_{\text {vac }}$ value $(2.39 \mathrm{eV})$ for the $\mathrm{Cu}$-doped system is $0.89 \mathrm{eV}$ smaller than the first $E_{\text {vac }}$ value for undoped ceria bulk. We will find that this decrease is dominated by dopant-induced electronic structure changes. Also here additional calculations were performed to pinpoint the respective contributions from strain and electronic effects. An $\mathrm{O}$ atom was removed rigidly (no relaxation was allowed) from the optimized $\mathrm{Ce}_{0.97} \mathrm{Cu}_{0.03} \mathrm{O}_{1.97}$ system, creating $\mathrm{Ce}_{0.97} \mathrm{Cu}_{0.03} \mathrm{O}_{1.94}$, which was subsequently allowed to relax. The relaxation energy was found to be $1.05 \mathrm{eV}$, i.e. $0.35 \mathrm{eV}$ smaller than that of the first vacancy of undoped ceria $(1.40 \mathrm{eV})$. Since the total lowering of $E_{\text {vac }}$ for the second vacancy in Cu-doped ceria is $0.89 \mathrm{eV}$ relative to the first vacancy in 
undoped ceria (cf. Table I), we conclude that dopant-induced changes in the electronic structure decrease $E_{\text {vac }}$ by $1.24 \mathrm{eV}(0.35 \mathrm{eV}+0.89 \mathrm{eV})$.

In summary, both the first and second $E_{\mathrm{vac}}$ energies in our $\mathrm{Cu}$-doped bulk ceria samples are smaller than $E_{\text {vac }}$ for undoped ceria $(3.28 \mathrm{eV})$. For the first vacancy, the lowering is as large as $2.98 \mathrm{eV}$ and our analysis shows that about half of this decrease can be attributed to electronic effects $(53 \%)$ and half $(47 \%)$ to large structural relaxation when the $\mathrm{Cu}$ dopant is present. For the second vacancy, the $E_{\mathrm{vac}}$ lowering is $0.89 \mathrm{eV}$ compared to the same undoped ceria value $(3.28 \mathrm{eV})$. Here the electronic effects are responsible for $100 \%$ of the decrease (and more), since the smaller relaxation energy actually increases the $E_{\mathrm{vac}}$ value compared to undoped ceria.

Fig. 4a displays the total density of states (TDOS) for the stoichiometric $\mathrm{CeO}_{2}$ bulk. Undoped $\mathrm{CeO}_{2}$ is an insulator with a calculated $\mathrm{O} 2 p$-Ce $4 f$ gap of $\sim 2.2 \mathrm{eV}$ with the functional we use here. The valence band has mostly $\mathrm{O} 2 p$ character with some contribution from Ce $4 f 5 d$ and the sharp peak above the valence band is from the Ce $4 f$ states.

The TDOS for partially reduced $\mathrm{CeO}_{2}$ bulk is shown in Fig. 4b. New vacancy states (occupied Ce $4 f$ states) appear below the Fermi energy. As in previous discussions in the literature (e.g. Ref. [20]), the electrons that occupy the new gap states are exactly localized on two of the Ce cations neighboring the oxygen vacancy, reducing them from + IV to + III, which is confirmed by the corresponding spin density distributions shown in Fig. 5a.

The TDOS for the Cu-doped unreduced ceria bulk is shown in Fig. 4c. Compared to the undoped system in Fig. 4a, two new peaks emerge above the Fermi level, in the range of 0 to 1.1 $\mathrm{eV}$. The corresponding sliced (or partial) electron density images (Fig. 5b) and the Bader charge analysis show that the low-lying of these unoccupied peaks is an oxygen hole state (1.00 electron) and the peak close to $1 \mathrm{eV}$ consists of two $\mathrm{Cu}-\mathrm{O}$ states (2.00 electrons). The oxygen hole state has $\mathrm{O} 2 p$ character and is spread over three oxygen atoms (not neighbors of $\mathrm{Cu}$ ), and the $\mathrm{Cu}-\mathrm{O}$ states mainly have $\mathrm{Cu} 3 d$ and $\mathrm{O} 2 p$ character and are distributed on the $\mathrm{Cu}$ dopant and its four $\mathrm{O}$ neighbors. These unoccupied states can be expected to serve as electron sinks to accommodate additional excess electrons left by the removal of oxygen atoms, thereby facilitating the oxygen vacancy formation. As we will see, only two of these three states will be utilized when the first and second $\mathrm{O}$ vacancies are formed in $\mathrm{Cu}$-doped ceria. When the first vacancy is formed, Figs. $4 \mathrm{~d}$ and $5 \mathrm{c}$ show that the oxygen hole state and one of the unoccupied $\mathrm{Cu}-\mathrm{O}$ states from Fig. $4 \mathrm{c}$ become occupied.

The $\mathrm{Cu}$ charge changes by about 0.14 as we go from Fig. $4 \mathrm{c}$ to $4 \mathrm{~d}$. Thus, the Bader charge analysis shows that the charge on the $\mathrm{Cu}$ dopant decreases from +1.20 in the unreduced bulk $\left(\mathrm{CuCe}_{31} \mathrm{O}_{64}\right)$ to +1.06 in the bulk with the first $\mathrm{O}$ vacancy $\left(\mathrm{CuCe}_{31} \mathrm{O}_{63}\right)$, which is closed to that in $\mathrm{CuO}$ bulk (+1.03). In fact, stoichiometrically, $\mathrm{CuCe}_{31} \mathrm{O}_{63}$ is equivalent to $\mathrm{Ce}_{31} \mathrm{O}_{62}-\mathrm{CuO}$.

Two $\mathrm{O}$ vacancies have been created in Fig. 4e. The polarized gap peaks in the region from -0.7 to $0.0 \mathrm{eV}$ consists of two contributions: (i) occupied (spin up) $\mathrm{Cu}-\mathrm{O}$ states which were occupied already for one $\mathrm{O}$ vacancy and (ii) two new peaks corresponding to two occupied $4 f$ states on the two new $\mathrm{Ce}^{3+}$ ions, marked by hash marks in Fig. 3. We have consequently labeled the new gap states "occupied Ce4f" in Fig. 4e. The corresponding spin charge density (Fig. 5d) shows that the occupied Ce $4 f$ states are similar to those in partially reduced ceria (Fig. 5a), with two $\mathrm{Ce}^{3+}$ ions residing next to the vacancy (vacancies). According to the Bader charge analysis, the $\mathrm{Cu}$ dopant's charge changes very slightly (from +1.06 to +1.03 ) when the second vacancy is formed, in line with the $\mathrm{Cu}-\mathrm{O}$ states not being much affected. 
The Ce $4 f$ states that become occupied in Fig. 4 e lie closer to the valence band edge than the Ce $4 f$ states in Fig. 4b. This trend is constistent with our discussion above about electronic effects (new states and/or shifts of levels) on the $E_{\mathrm{vac}}$ values and the lowering of the second $E_{\mathrm{vac}}$ in Cu-doped bulk ceria compared to the first $E_{\text {vac }}$ in undoped bulk ceria. However, the shift of the Ce $4 f$ states in Fig. 4 is too small to be the sole reason for this lowering.

In summary, we have found that the $\mathrm{O}$ hole state and $\mathrm{Cu}-\mathrm{O}$ states, play a major role as electron sinks when the first $\mathrm{O}$ vacancy is formed in $\mathrm{Cu}$-doped ceria. When the second vacancy is formed, the Ce $4 f$ states are the most important electron sink (just as they are for the first vacancy in undoped ceria), but we cannot fully explain the lowering of the second vacancy compared to the first vacancy in undoped $\mathrm{CeO}_{2}$.

\subsection{Comparison between Cu-doped bulk and surface}

Unreduced and reduced $\mathrm{Cu}$-doped ceria(111) surfaces were studied by us in Ref. [12], using a similar computational procedure as here. Our surface model was a 3-dimensional lamellar slab system and the outermost slab layer on each side consisted of $\mathrm{O}$ atoms. On one side of the $\mathrm{CeO}_{2}(111)$ slab, one $\mathrm{Ce}$ atom in the outermost $\mathrm{Ce}$ layer was replaced by a $\mathrm{Cu}$ atom, which corresponds to a dopant concentration of $8 \%$, i.e. $\mathrm{Cu}_{0.08} \mathrm{Ce}_{0.92} \mathrm{O}_{2}(111)$.

Starting from its original Ce position, the $\mathrm{Cu}$ dopant in Ref. [12] was found to relax inwards, ending up in the subsurface oxygen layer and adopting a nearly planar structure coordinated by four $\mathrm{O}$ ions (one surface oxygen, two subsurface oxygen and one third-layer oxygen). The coordination figure at the $\mathrm{Cu}$-doped surface is very similar to that of the $\mathrm{Cu}$-doped bulk system (cf. Table I). The charge of the Cu-dopant is +1.15 in the surface system compared to +1.20 in the bulk; both are in the $\mathrm{Cu}(+\mathrm{II})$ state.

The $E_{\mathrm{vac}}$ value for the undoped ceria(111) surface is about $0.40 \mathrm{eV}$ smaller than in the bulk (Table I). Two surface $\mathrm{Ce}^{4+}$ cations next to the vacancy are reduced to $\mathrm{Ce}^{3+}$ (we have not investigated any other possible configurations of the excess electrons associated with the vacancy, as was done in Ref. [28]). For the Cu-doped ceria(111) surface, either a NN surface oxygen atom residing $1.85 \AA$ from $\mathrm{Cu}$ or a NNN surface oxygen at $3.70 \AA$ from $\mathrm{Cu}$ was removed. In the former case, no large structural changes occurred, while for the NNN O vacancy, the $\mathrm{Cu}-\mathrm{O}$ bond lengths elongate by about $0.1 \AA$. Just as for the bulk, the first $E_{\text {vac }}$ values are small, and the NNN vacancy location is the most favorable (forms almost spontaneously; Table I). Also a second vacancy forms more easily when $\mathrm{Cu}$ is present in the surface region. The local 4-coordination is kept for the NNN single vacancy as well as for the vacancy dimer.

\section{Conclusions}

Our PAW/PBE+U results for $\mathrm{Cu}-$ doped ceria show that:

a. The $\mathrm{Cu}$ dopant adopts a 4-coordinated, almost planar, $\mathrm{Cu}-\mathrm{O}$ coordination both in the unreduced system and when one or two $\mathrm{O}$ vacancies are present.

b. The charge of the $\mathrm{Cu}$ dopant varies rather little $(<0.2$ electrons) for all the $\mathrm{Cu}$-doped system studied here. In all cases we find $\mathrm{Cu}^{2+}$ species, or rather $\mathrm{Cu}(+\mathrm{II})$, and we do not find the formation of $\mathrm{Cu}^{+}$in the current studies (which we found earlier for the $\mathrm{Cu}$ adatom); 
c. Out of the two electrons left over when the first $O$ vacancy is formed, one localizes in an $\mathrm{O} 2 \mathrm{p}$ hole state which belongs to three oxygen atoms which are next-nearest neighbors to the $\mathrm{Cu}$ atom, and the other localizes in a $\mathrm{Cu}-\mathrm{O}$ orbital. As for the two additional electrons that are left over when the second $O$ vacancy is formed, each localizes on a $\mathrm{Ce}$ atom neighboring the new $\mathrm{O}$ vacancy, creating two $\mathrm{Ce}^{3+}$ ions;

d. $E_{\mathrm{vac}}$ is much reduced by the $\mathrm{Cu}$ dopant, for both the first and the second $\mathrm{O}$ vacancies, suggesting that the $\mathrm{Cu}$ dopant can serve as the seed for the formation of oxygen vacancy clusters;

e. The large lowering of the first $\mathrm{O}$ vacancy induced by the $\mathrm{Cu}$ dopant is in part (about 50\%) due to dopant-induced structural relaxation, and in part to the charge balance requirement, i.e. the filling of the unoccupied $\mathrm{O} 2 p$ hole state and $\mathrm{Cu}-\mathrm{O}$ states that are created by the dopant because of the lower valence of $\mathrm{Cu}^{2+}$ compared to $\mathrm{Ce}^{4+}$;

f. For the second $\mathrm{O}$ vacancy, the dopant-induced lowering of $E_{\mathrm{vac}}$ is partly due to the lowering of the $\mathrm{Ce} 4 \mathrm{f}$ states compared to pure $\mathrm{CeO}_{2-\mathrm{x}}$.

Many of these conclusions should be generally valid for an aliovalent transition metal dopant (i.e. with lower valence than the host cations), which we expect to generally be potent in facilitating the $\mathrm{O}$ vacancy formation in a reducible oxide. Charge compensation, structural relaxation and available $\mathrm{Cu}-\mathrm{O}$ states all play a role in the mechanisms responsible for lowering the $\mathrm{O}$ vacancy formation energies (compared to the undoped case), but to different degrees when the first and second oxygen vacancies are formed. The $\mathrm{Cu}$-doped bulk and ceria(111) surface systems are found to display very consistent properties.

\section{Acknowledgments}

This work was supported the National Natural Science Foundation of China (Grant No.10674042), the Swedish Research Council (VR), the Innovation Scientists and Technicians Troop Construction Projects of Henan Province, China (Grant No. 104200510014), and the Swedish Research Links Programme funded by the Swedish International Development Cooperation Agency (Sida). ZL also acknowledges the LiSUM (Linking Sino-European Universities through Mobility) program for a scholarship and travel grant to Sweden. 


\section{References}

[1] X. Wang, J. A. Rodriguez, J. C. Hanson, D. Gamarra, A. Martínez-Arias, M. Fernández-García, J. Phys. Chem. B, 110 (2006) 428

[2] T. Zhu, L. Kundakovic, A. Dreher, M. Flytzani-Stephanopoulos, Catal. Today, 50 (1999) 381

[3] J. Beckers, G. Rothenberg, Dalton Trans., 14 (2008) 6573

[4] S. Park, J. M. Vohs, R. J. Gorte, Nature, 404 (2000) 265

[5] S. McIntosh, R. J. Gorte, Chemical Reviews, 104 (2004) 4845

[6] G. Avgouropoulos, T. Ioannides, H. Matralis, Appl. Catal. B: Environ., 56 (2005) 87

[7] P. Djinović, J. Batista, A. Pintar, Appl. Catal. A: Gen., 347 (2008) 23

[8] A. Gayen, K. R. Priolkar, A. K. Shukla, N. Ravishankar, M. S. Hegde, Mater. Res. Bull., 40 (2005) 421

[9] P. Bera, K. R. Priolkar, P. R. Sarode, M. S. Hegde, S. Emura, R. Kumashiro, N. P. Lalla, Chem. Mater., 14 (2002) 3591

[10] X. Wang, J. A. Rodriguez, J. C. Hanson, D. Gamarra, A. Martinez-Arias, M. Fernandez-Garcia, J. Phys. Chem. B, 109 (2005) 19595

[11] V. Shapovalov, H. Metiu, J. Catal., 245 (2007) 205

[12] Z. Yang, B. He, Z. Lu, K. Hermansson, J. Phys. Chem. C, 114 (2010) 4486

[13] M. M. Branda, N. C. Hernandez, J. F. Sanz, F. Illas, J. Phys. Chem. C, 114 (2010) 1934

[14] G. Kresse, J. Hafner, Phys. Rev. B, 47 (1993) 558

[15] G. Kresse, J. Furthmüller, Phys. Rev. B, 54 (1996) 11169

[16] P. E. Blöchl, Phys. Rev. B, 50 (1994) 17953

[17] J. P. Perdew, J. A. Chevary, S. H. Vosko, K. A. Jackson, M. R. Pederson, D. J. Singh, C. Fiolhais, Phys. Rev. B, 46 (1992) 6671

[18] C. W. M. Castleton, J. Kullgren, K. Hermansson, J. Chem. Phys., 127 (2007) 244704

[19] S. L. Dudarev, G. A. Botton, S. Y. Savrasov, C. J. Humphreys, A. P. Sutton, Phys. Rev. B, 57 (1998) 1505

[20] M. Nolan, S. Grigoleit, D. C. Sayle, S. C. Parker, G. W. Watson, Surf. Sci., 576 (2005) 217

[21] G. Henkelman, A. Arnaldsson, H. Jónsson, Comput. Mater. Sci., 36 (2006) 354

[22] L. Eyring: Handbook on the Physics and Chemistry of Rare Earths, North-Holland, Amsterdam, 1979.

[23] H. J. Monkhorst, J. D. Pack, Phys. Rev. B, 13 (1976) 5188

[24] S. Asbrink, A. Waskowska, J. Phys.: Condens. Matter, 3 (1991) 8173

[25] D. A. Andersson, S. I. Simak, N. V. Skorodumova, I. A. Abrikosov, B. Johansson, Appl. Phys. Lett., 90 (2007) 031909

[26] Z. X. Yang, D. W. Ma, X. H. Yu, K. Hermansson, Eur. Phys. J. B, 77 (2010) 373

[27] Y. Zhang, S. Andersson, M. Muhammed, Appl. Catal. B: Environ., 6 (1995) 325

[28] M. V. Ganduglia-Pirovano, J. L. F. Da Silva, J. Sauer, Phys. Rev. Lett., 102 (2009) 026101 
Table I. O vacancy formation energy $\left(E_{\mathrm{vac}}\right)$ for the undoped and $\mathrm{Cu}$ doped ceria systems (bulk from this study and surface from Ref. [12]); The Bader charge of the $\mathrm{Cu}$ dopant, and the $\mathrm{Cu}-\mathrm{O}$ bond lengths in the first coordination around $\mathrm{Cu}$ are listed in columns three and four.

\begin{tabular}{lccc}
\hline \multicolumn{1}{c}{ Systems } & $\begin{array}{c}\boldsymbol{E}_{\mathbf{v a c}} \\
(\mathrm{eV})\end{array}$ & $\begin{array}{c}\text { Cu charge } \\
(e)\end{array}$ & $\begin{array}{c}\boldsymbol{R}(\mathbf{C u}-\mathbf{O}) \\
(\AA)\end{array}$ \\
\hline CuO bulk & - & +1.02 & $4 \times 1.95$ \\
Undoped ceria & 3.28 & - & - \\
Bulk model & 2.93 & - & - \\
(111) surface model & & & $4 \times 1.87$ \\
Unreduced Cu doped ceria & - & +1.20 & $3 \times 1.85,1.89$ \\
Bulk model & - & +1.15 & \\
(111) surface model & & & $2 \times 1.90,1.92$ \\
1st O vacancy in NN position of Cu & & +0.98 & $2 \times 1.86,1.93$ \\
Bulk model & 0.98 & +0.94 & \\
(111) surface model & 0.67 & & $2 \times 1.93,1.95,2.00$ \\
1st O vacancy in NNN position of Cu & & & \\
Bulk model & 0.30 & +1.06 & $1.93,1.95,1.96,1.99$ \\
(111) surface model & 0.04 & +1.06 & \\
2nd O vacancy & & & \\
Bulk model & 2.39 & +1.03 & \\
(111) surface model & 2.17 & & \\
\hline
\end{tabular}




\section{Figures}

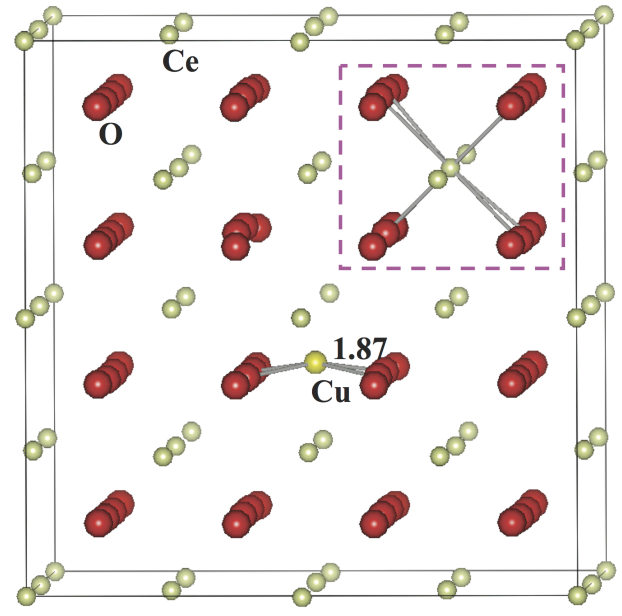

(a) Cu-doped $\mathrm{CeO}_{2}$ bulk

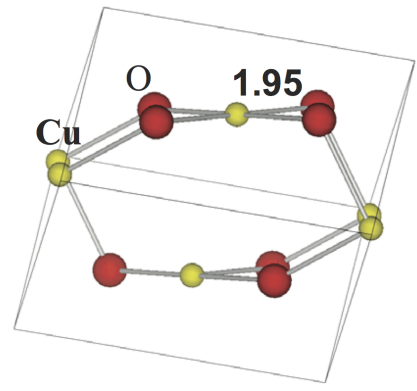

(b) $\mathrm{CuO}$

Fig. 1 (Color online) (a) The relaxed structure for the $\mathrm{Cu}$-doped $\mathrm{CeO}_{2}$ bulk and the additional $\mathrm{Ce}-\mathrm{O}$ bonds in the pink rectangular box are guides to the eye marking the cubic crystallographic structure of $\mathrm{CeO}_{2}$; (b) relaxed $\mathrm{CuO}$ bulk structure. Bond lengths given in the figures are in $\AA$.

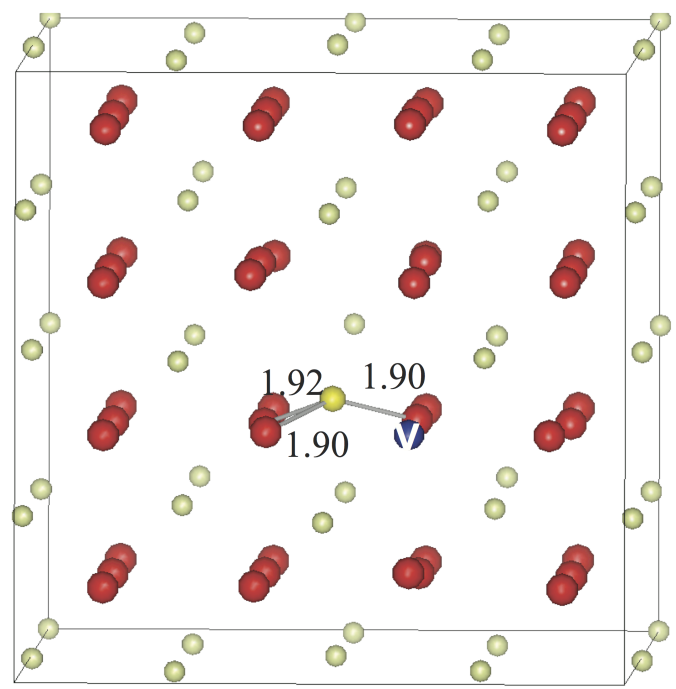

(a) O vacancy $\mathrm{NN}$ to $\mathrm{Cu}$

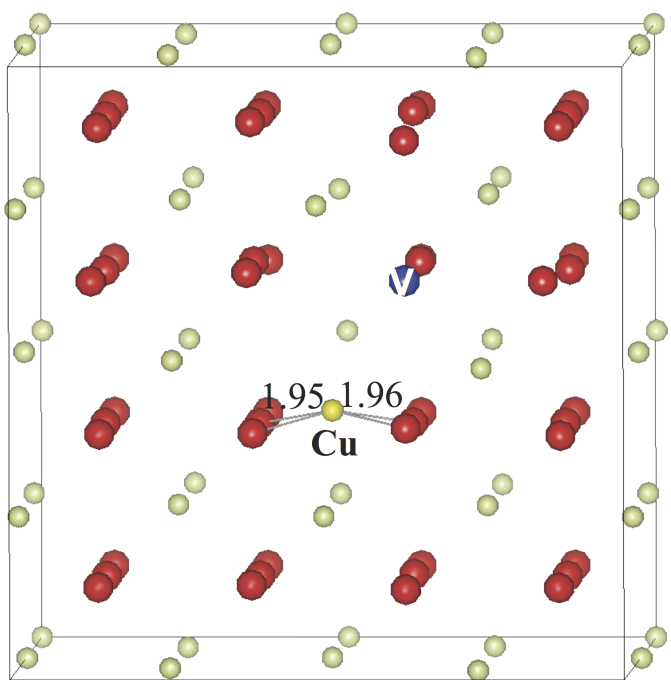

(b) O vacancy next-NN to $\mathrm{Cu}$

Fig. 2 (Color online) Relaxed structures for partially reduced Cu-doped bulk ceria for two different locations of a single O vacancy (a) $\mathrm{NN}$ and (b) NNN to the Cu dopant. Hereafter, the blue sphere represents the $\mathrm{O}$ vacancy and "\#” (in forthcoming figures) denotes a reduced Cerium $\left(\mathrm{Ce}^{3+}\right)$. 


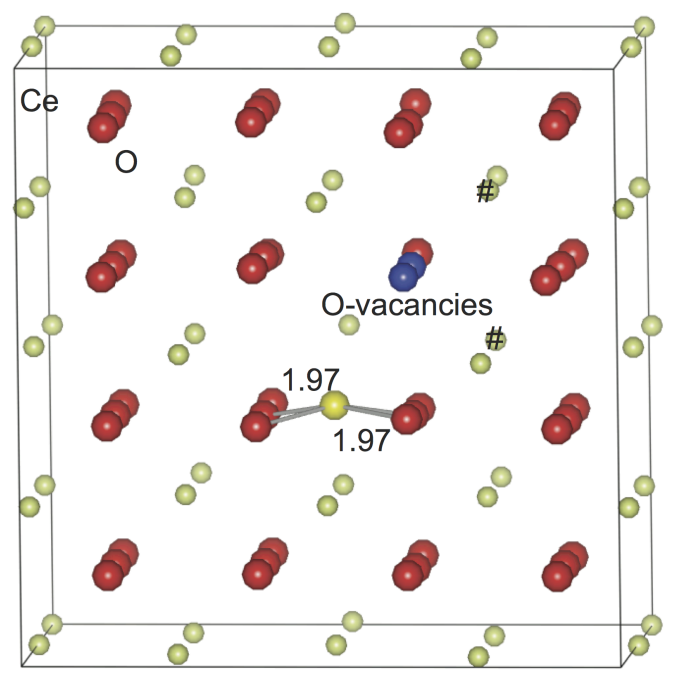

Fig. 3 (Color online) Relaxed structure for partially reduced $\mathrm{Cu}$-doped ceria bulk with two $\mathrm{O}$ vacancies.

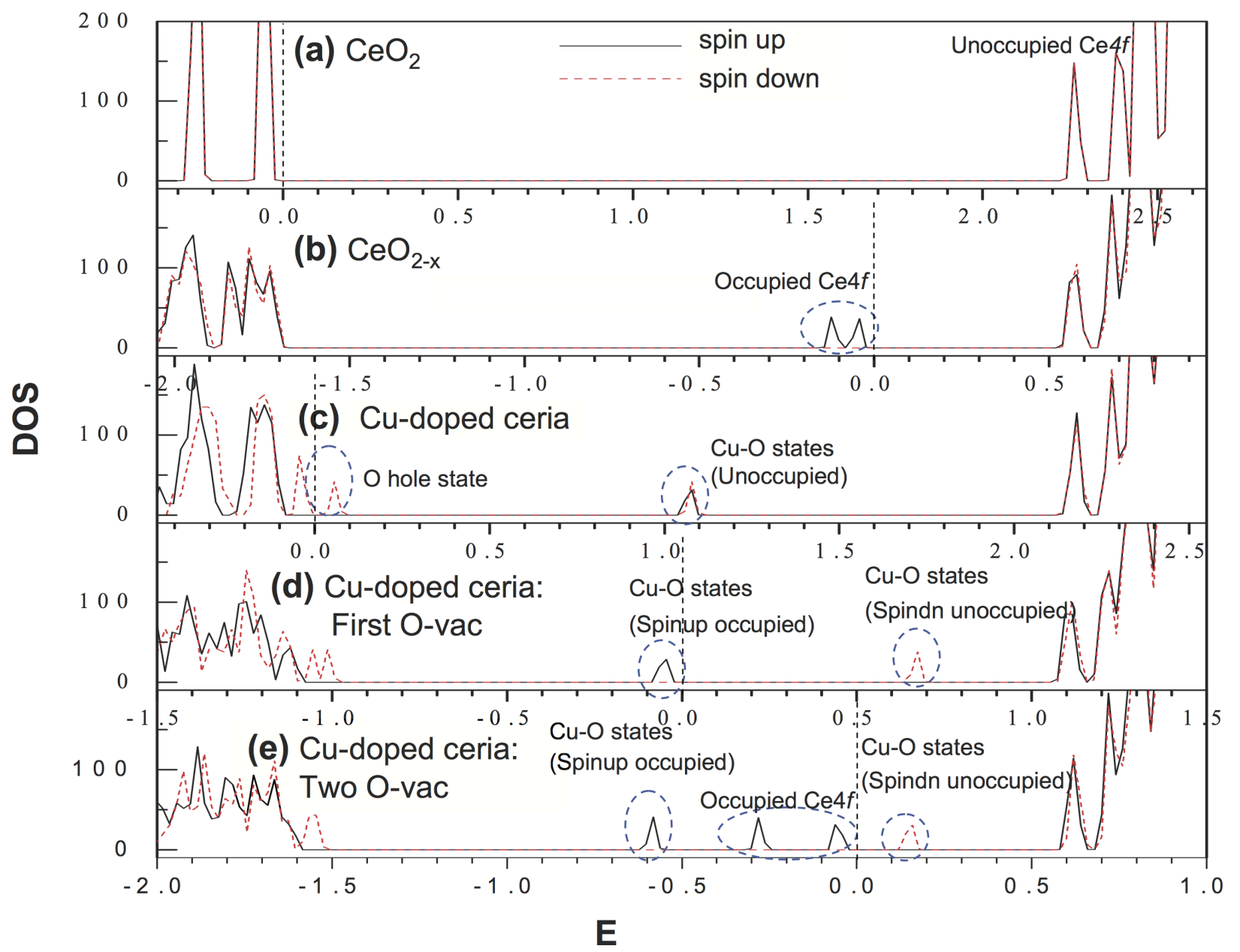

Fig. 4 The total density of states (TDOS). Hereafter, solid black and dashed red curves represent the DOSs from the spin up and spin down channels, respectively. The lower edge of the unoccupied Ce4f band has been used to align the five TDOS graphs. The vertical dashed line represents the Fermi energy (i.e. the highest occupied orbital energy).

(a) the unreduced $\mathrm{CeO}_{2}$ bulk;

(b) the partially reduce $\mathrm{CeO}_{2}$ bulk (denoted as $\mathrm{CeO}_{2-\mathrm{x}}$ ); 
(c) the unreduced $\mathrm{Cu}$-doped ceria bulk;

(d) the partially reduced $\mathrm{Cu}$-doped ceria bulk with first $\mathrm{O}$ vacancy;

(e) the partially reduced $\mathrm{Cu}$-doped ceria bulk with two $\mathrm{O}$ vacancies.

Undoped ceria, 1 O-vac Cu-doped ceria

Occupied Ce4f states (cf. Fig 4b) Unoccupied O hole state and Cu-O states (cf. Fig 4c)
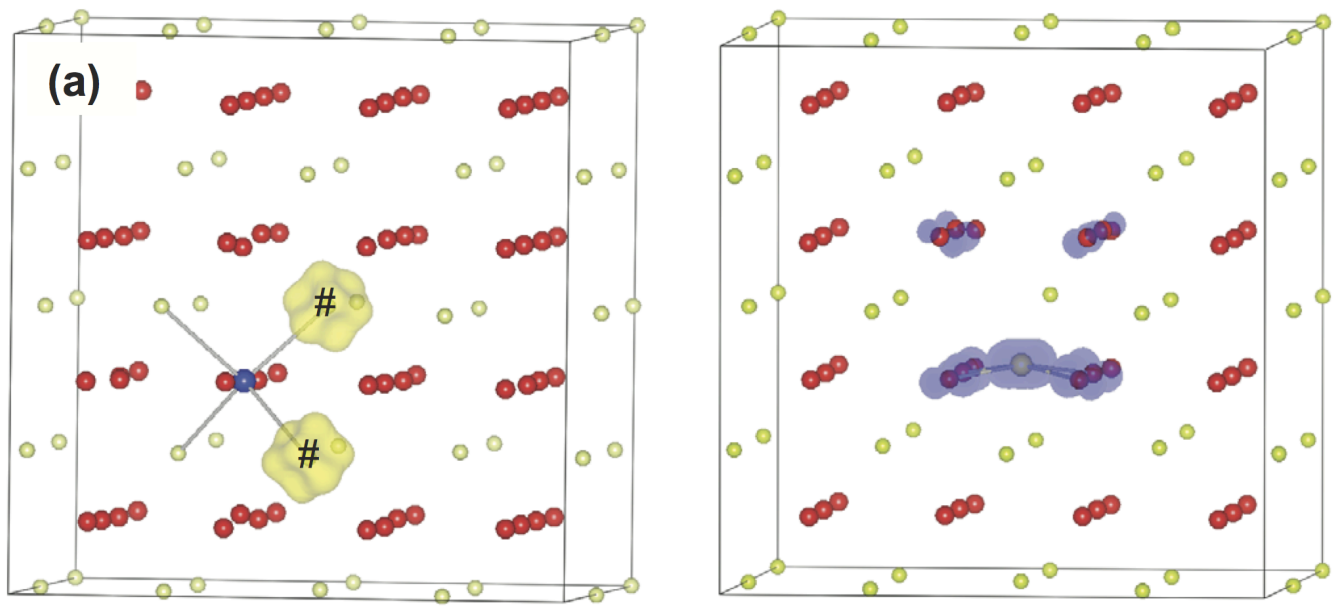

Cu-doped ceria, 1 O-vac, Occupied Cu-O state (cf. Fig 4d)

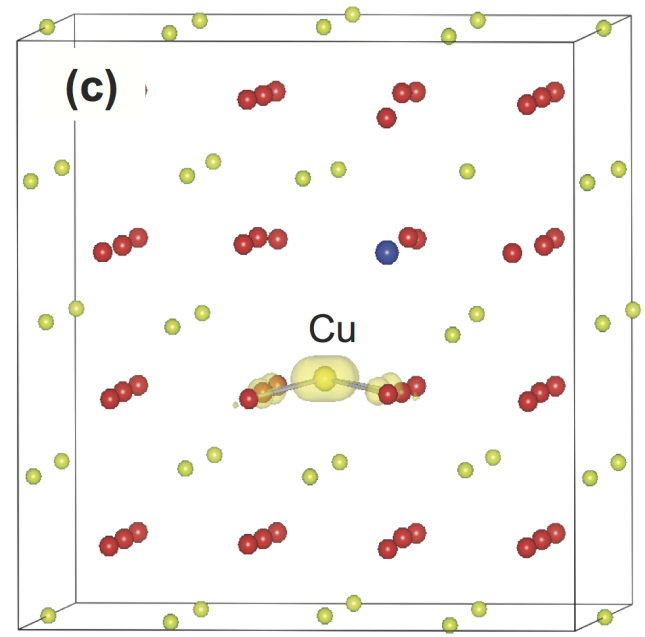

Cu-doped ceria, 2 O-vac, Occupied Ce4f and Cu-O states (cf. Fig 4e)

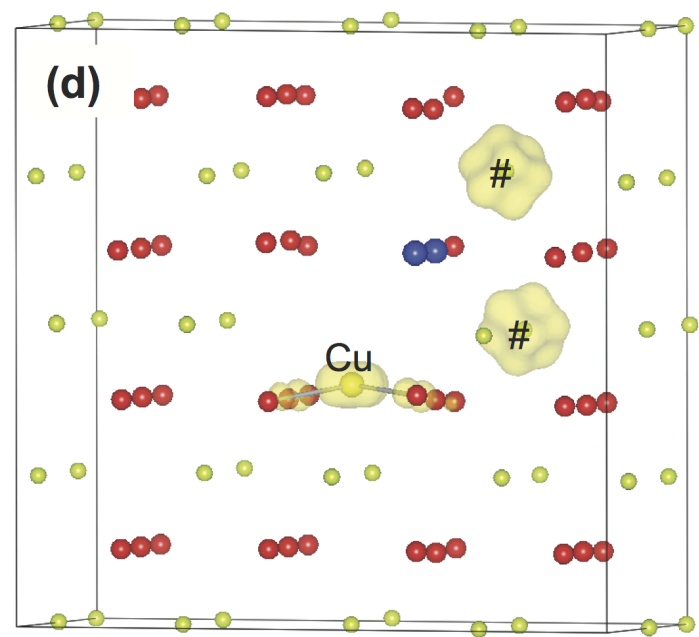

Fig. 5 (Color online) The partial or spin electron densities for the corresponding systems shown in

Fig. 4. The isosurface value displayed is $0.02 \mathrm{e} / \AA^{3}$, the occupied densities are presented in yellow color, while the unoccupied states are presented in blue color.

(a) The spin charge density for the partially reduced $\mathrm{CeO}_{2}$ bulk (corresponding to the system in Fig. 4b);

(b) The partial charge density corresponding to the unoccupied states ( $\mathrm{O}$ hole states and $\mathrm{Cu}-\mathrm{O}$ states) in Fig. 4c, namely the energy window from 0.0 to $1.1 \mathrm{eV}$;

(c) The partial charge density corresponding to the occupied gap states in Fig. 4d, namely the spin up of $\mathrm{Cu}-\mathrm{O}$ states in the energy window from -0.1 to $0.0 \mathrm{eV}$;

(d) The partial charge density corresponding to the occupied gap states in Fig. 4e, namely the spin up of $\mathrm{Cu}-\mathrm{O}$ state and $\mathrm{Ce} 4 f$ states in the energy window from -0.6 to $0.0 \mathrm{eV}$. 